\title{
Qualitative Methods and Visualizations in the Study of Friendship Networks
}

\author{
by Elisa Bellotti \\ University of Manchester \\ Sociological Research Online, 21 (2), 2 \\ $<$ http://www.socresonline.org.uk/21/2/2.html> \\ DOI: $10.5153 /$ sro.3936
}

Received: 24 Sep 2015 I Accepted: 12 May 2016 I Published: 31 May 2016

\begin{abstract}
One of the most powerful aspects of social network data is the fact that they can reproduce social relationships in a formal and comparable way. Relational matrices abstract from the hustle and bustle of everyday interaction, and systematise information in terms of presence or absence of ties expressing them in a directed or undirected, binary or valued form. While the formal approach represents an advantage of social network analysis, as it allows bracketing off the idiosyncratic and subjective content of social structures, the mathematization of the complex nature of social relationships has also been criticised for the lack of engagement with the subjective meaning and context of relationships. Such stream of critique has called for an increase of use of qualitative methods in social network research. The first goal of the paper is to address these critiques by rebalancing the argument and showing how social network analysis has always engaged with both formal and contextual aspects of social structures. The paper reviews some theoretical perspectives that discuss and systematise a mixed method approach, and explores the methodological advantages of using network visualizations together with qualitative interviews in the collection, analysis and interpretation of personal networks. The advantages of adopting a mixed method approach are illustrated over some examples of friendship networks of 23 single male and female people collected in Milan, Italy, in 2005. A classic name generator is used to reconstruct their egonets of friends, and the visualization is adopted as the input for in-depth interviews with specific attention devoted to the meaning of friendship relationships, the kind of resources they offer, the conflicts and constrains they entail, and how they have developed and evolved over time. By comparing information obtained respectively with name generators and in-depth interviews, the paper shows how the mix of data improves and specify the understanding of personal networks.
\end{abstract}

Keywords: Egonets, Social Network Analysis, In-Depth Interviews, Network Visualization, Mixed Methods, Friendship

\section{Introduction}

Social network analysis has been widely used in the investigation of personal communities, as it allows observing the overlapping structure of relations individuals are embedded in, of which they may not be entirely aware. This is because while people understand the entangled nature of their social lives, they rarely reason in structural terms, reflecting on the relationships that link together the people they are related to. Individuals are more or less aware of these relationships, and they can, to a certain extent, account for them, but even when they can describe the ties that nest around them they usually do not reach an "outsider" perspective of the full structural shape of their personal network: they are rather limited to an "insider" view, of what goes on in dyads (Chiu and West 2007), and often do not consciously reflect on the nature and availability of these dyads either. This is why social network analysis can add valuable information to the study of social embeddedness, because even when data are collected from individuals, the formalization and visualization of the structure of overlapping dyads provide a perspective that interviewees are not familiar with.

This strength of network analysis has however been sometimes criticised as an arid way to simplify the complex nature of personal relationships. (Mønsted 1995, Coviello 2005). As Edwards (2010) points out, the debate on how to address the problem of measuring social relationships in a quantifiable way has stimulated theoretically driven calls for mixed methods within sociology (Emirbayer and Goodwin 1994; Mische 2003; Crossley 2010) and anthropology (Riles 2001; Knox et al. 2006). These calls have seen a subsequent rise in methodological debates on how to mix qualitative methods with social network analysis (see for example, the dedicated special issue of Sociologica, 1, 2010, but also Hollstein 2011, Bellotti 2015, D'Angelo and Ryan 2016).

The first aim of this paper is to address these critiques by rebalancing the argument and showing how social network analysis has always engaged with both formal and contextual aspects of social structures. Secondly it reviews the theoretical and methodological debate that has recently flourished around the issue of mixing qualitative methods with formal social network analysis in the study of personal networks. It does so by critically discussing the impact of relational sociology (Emirbayer 1997) on the debate, and by briefly reviewing some recent articles that have discussed the mixed method approach. Subsequently it illustrates the strength of 
qualitative methods, and specifically in-depth interviews, combined with two methods of visualization of egonets, by using some examples of friendship networks of 23 single male and female people collected in Milan, Italy, in 2005. The discussion over the methodological advantages of the approach is organised in three sections: collecting network data using a name generator, the visualization of the egonet, in-depth interviews and a target of concentric circles (Kahn and Antonucci 1980); analysing networks mixing formal measures with narratives and visualizations; and interpreting results combining information from all methods. The distinction between data collection, analysis and interpretation emerges from the observation that while qualitative information can be mixed with social network analysis in all the phases, in some cases the mix has been adopted in only one of them (Edwards 2010). It is therefore important to discuss how and why to mix methods at different stages of the research, as in each step the combination of narratives with network measures and visualizations can provide different and complementary advantages. The conclusions then turn to the discussion of some of the limits and difficulties in mixing methods in social network research.

\section{The content of ties. Relational sociology and mixed methods}

Despite the development of sophisticated methods for the formal analysis of social networks and their applications in various disciplines, a critical debate flourished that called for an equal development of techniques for the analysis of the subjective side of network structures. In such critique, network formalizations are claimed to be limited in showing how intentional and creative action contributes to the constitution of the web of relationships that in turn shape the opportunities for such subjective action (Emirbayer and Goodwin 1994). The focus on the structural elements that define the relations among sets of positions, as theorise by White et al. (1976), is supposed to hide the importance of the cultural context in which relationships and interactions take place (Brint 1992). What such critics fail to recognise, though, is that the formal approach of social network analysis has never claimed to be the only and unique way to investigate social relations and social structures. On the contrary, formal social network analysis has always underlined the importance of using complementary methods, and it would be incorrect to consider the whole perspective inadequate for the lack of engagement with the contextual study of subjectivity.

Such critics have however stimulated the work of what Knox et al. (2006) identify as a new generation of social network researchers, who focused on the reintroduction of the cultural and discursive foundations of social network analysis. This generation, who loosely belongs to the so called 'relational sociology' ${ }^{[1]}$ (Emirbayer 1997; Crossley 2011), instead of developing outside and against the social network tradition, has been deeply inspired by the work of Harrison White and Charles Tilly, who, during the 90s, played a crucial role in broadening the spectrum of analysis of network structures and engineering the emergence of what might be called 'the New York School' of relational sociology (Mische 2011). In particular, White's work on identity and its narrative construction (White 2008 [1992]), which follows his equally fundamental work on formal measurement of positions in networks (White et al. 1976), can be considered at the core of this focus on cultural elements in social network analysis.

The point to take here is that although the New York School, and the revival of White's later work, have indeed stimulated a series of reflections and of theoretical and methodological systematization of the two components of social network analysis, the formal and the contextual, it would be misleading to claim that the former component has dominated the second: on the contrary, social network analysis can count on a long and established tradition of studies that, by combining mathematical methods and qualitative data, explore the contextualised nature of social relations. This tradition can be dated back to the seminal work of the Manchester School of Anthropology, where the attention was dedicated to the study of social networks in natural settings. The Manchester School, which flourished in the late 60s under the influence of John Barnes, Clyde Mitchell, and other significant scholars, relied mainly of the use of ethnographic observations as tools for data collection (Mitchell 1969). However, it was neither the first nor the only one to use qualitative data in the study of social networks. A notable antecedent is the famous study of an Italian slum in Boston (Whyte 1943).

In the past 30 years a very large proportion of publications have been indeed dedicated to the development of formal methods of analysis, whose applications have then spread around in many substantive fields where the interest is less into developing analytical methods and more into using them to answer specific theoretical questions. While the development of formal methods requires mathematical and statistical work often detached from a concrete social context, when applied in various fields social network analysis undoubtedly benefits from a combination of formal models and qualitative accounts that enlighten each other and illustrate contextual mechanisms (McCarty 2010). In these situations, much work has used qualitative techniques to locate and understand formal networks in their social and cultural contexts.

Some of these works have explicitly discussed the adoption of mixed methods in network research as a way to overcome the limits of single methods in their respective fields of analysis (Mische and White 1998; Martinez et al. 2003; Jack 2005; Woo Park and Kluver 2009; Lubbers et al. 2010). Others, given their substantive focus on specific research topics, have not stressed the accent over the mixed methods aspects, possibly producing the perception of a less common adoption of qualitative methods in network research. Examples of studies that have silently made use of qualitative methods are the paper of Lazega et al. (2008), and the paper by Bodin and Tengö (2012), where the combination of qualitative observation and social network analysis is not the main scope of the articles, and therefore is not mentioned in the abstracts or in the keywords. Conversely, a general lack of interest from mainstream qualitative researchers in approaching and adopting a network perspective has been noted (Kirke 2010), which is likely to be responsible for the perceived marginalization of qualitative methods. The mainstream trends of qualitative research, especially in their methodological 
discussions, have been predominantly engaged in paradigmatically rejecting any kind of data formalization, and have therefore avoided any consistent contribution to social network studies.

As I said before, the New York School and more broadly relational sociology (Crossley 2011) have stimulated a fruitful debate on how to mix methods in social network analysis, and such theoretical and methodological debate (Bellotti 2015) has produced various and useful ways of classify studies where the mix has been applied (see, for example, Edwards 2010 and Fuhse and Mützel 2011). In the introduction to the seminal book ' Mixed Methods Social Network Research (Dominguez and Hollstein 2014), Hollstein proposes a clear classification of mixed methods that combine social network analysis with qualitative tools. In her perspective, studies are considered mixed methods if they satisfy three conditions:

1. They have to be based on both quantitative and qualitative type of data, either by collecting them, or by converting one type of data into another;

2. They have to employ both quantitative and qualitative analytical strategies;

3. Data or analytical strategies have to be integrated at least in one stage of research, being data collection, data analysis or data interpretation (Hollstein 2014: 11).

This definition pays credit to the tradition of the mixed methods debate, which insists in the need for the combination of both quantitative and qualitative approaches for a truly mixed method approach. Tashakkori and Creswell, for example, defines mixed methods as "research in which the investigator collects and analyses data, integrates findings, and draws inferences using both qualitative and quantitative approaches or methods in a single study" (Tashakkori and Creswell 2007: 4). Indeed in the mixed method literature the stress has been on highlighting the advantages, but also the problems, of combining the ontological and epistemological positions of the quantitative and the qualitative traditions; and without doubt such stress is the outcome of the longstanding so called paradigm war (Guba and Lincoln 1994). However, such definition could also be relaxed and extended to any type of methodological mix, where the combined methods can be various tools without necessarily mixing the qualitative with the quantitative. It's the case, for example, of the paper of Ryan and colleagues (2014) that combines various qualitative methods, and similarly the paper of Tubaro, Ryan and D'Angelo (2016).

The case study discussed in this article can be considered a mixed method study as it makes uses of both quantitative and qualitative type of data; as it employs descriptive statistical strategies as well as interpretative methods; and as it uses both the analytical approaches in data collection, analysis and interpretation. Following the classifications proposed in the mixed method literature (Tashakkori and Teddlie 1998; Creswell and Plano Clark 2007), the study presented here adopts a conversion design that involves the transformation of qualitative data into quantitative one, but also falls into the category of embedded design as the qualitative approach is prevalent over the quantitative one.

In the next three sections the various phases of the research are introduced, and the methodological techniques discussed.

\section{Data collection}

3.1 The empirical study discussed in this article made use of the egonet approach, where information was collected from a series of independent focal agents in regards to their local neighbourhood. The study explored the friendship networks of a non-representative sample of 23 heterosexual singles living in Milan, aged between 25 and 35 years, 12 male and 11 female. The sample was selected according to the age (people aged between 25 and 35), gender (12 male, 11 females) and educational background (8 people with degree, 8 who left school after secondary education, 7 who left school after compulsory education). They were all born in Milan, but lived in different areas of the city. People were selected using snowball techniques with different starting contacts, so they did not know each other and were not known by the researcher before the interview.

3.2 For the data collection I adopted a classic version of the name generator (like the one used in 1998 GSS, see Marsden 2003), in which individuals are asked to name their friends (tie approach), to specify some of their attributes (alter approach), and to indicate the existence of relationships between them (structural approach, see Agneessens 2006; Crossley et al. 2015). In details, I collected names of people's friends, whatever the respondents' understanding of the term: no limit to the number of alters was set, and no standard definition of friendship was provided. Name interpreters (age, gender, where they live, where they were born, whom do they live with, if they are single or partnered, their educational level, what job they do and how long they have known ego for) were used to collect friends' attributes, and links between every pair of friends were recorded. The name generator was intentionally left open and undetermined, as I wanted people to name friends according to their own definition of the term, which is known to be highly variable (Fischer 1982). Network sizes thus vary both in terms of the number of friends people have, and in terms of the criteria they use to include people. resulting egonet graphs, visualised with Netdraw (Borgatti 2002), were used as inputs for in-depth interviews. Indepth interviews are a very common tool for data collection in qualitative research. They are often described as conversations with a purpose (Webb and Webb 1932) in which knowledge is constructed in the interaction between the researcher and the interviewee (Rorty 1980). The interviews used in this study focussed on the meaning of friendship ties, the kind of resources they offer, the conflicts and constrains they entail, and how they 
have developed and evolved over time. The interviewee was presented with the visualization of the egonet and asked to "talk about the friends named, starting from wherever you like". The discussion was organised around a funnel path of topics that went from general, "grand tour" questions, to questions about specifics (Spradley 1979), even if interviewees could cover the topics in any preferred order, and they were not forced to cover all of them. If a topic did not emerge either spontaneously or following the interviewer's inputs, it was simply recorded as nonrelevant for the interviewees. Likewise, if an interviewee discussed a topic that was not previously foreseen in the interview protocol, she was left talking about it, unless it was completely unrelated to the research questions. Topics were associated to personal experiences, relationship phases, normative aspects and ideal definitions of friendship, ranging from abstract concepts and ideal scenarios to concrete examples.

At the end of the interview the interviewees were provided with a paper sheet representing a target of concentric circles (similar to the one used by Spencer and Pahl 2006 and Hogan et al. 2007, see also Kahn and Antonucci 1980), where they placed the friends they discussed during the interview following the criteria of the closer they feel to friends, the inner the circles they were placed in. Interviewees were also allowed to add in the target any other person they wanted, regardless of the type of relationships: in many cases people added family ties, which were placed in inner circles in respect of friends, while others added more distant friends, acquaintances and colleagues who were not close enough to be named in the name generator, and therefore were not included in the network visualization.

A similar methodology was adopted by Spencer and Pahl (2006) in their research on friendship and social support. Spencer and Pahl combine the target of concentric circles with in-depth interviews, to explore the support network of sixty British men and women of different ages and different geographical and social background. Their study illustrates on one hand the great advantages of using a qualitative approach to study friendship ties, as it allows to overcome the 'difficulties in making senses of conflicting statistics about the average number of friends we are supposed to have' (Spencer and Pahl 2006: 4) when these is 'no clear agreement on what precisely the term friend means' (Spencer and Pahl 2006: 4). On the other hand it is also an example of the rejection by mainstream qualitative research of social network analysis tools, accused to place 'greater emphasis on features such as the size of the network or the frequency of contact between members, rather than on the content of the relationship' (Spencer and Pahl 2006: 45). The authors go on describing their data collection interview technique, which consisted in asking interviewees about their significant personal relationships and who they would turn to in particular circumstances (Spencer and Pahl 2006: 47). However, they seem to be unaware that the same interview technique, with the same questions, was used by Wellman (1979; 1990) in his study of the support networks of East Yorkers, which can be arguably considered a fine example of social network research.

The methodology adopted in this paper has the advantage of combining both the standardised tool of egonets, where the content is bracketed out to highlight the formal structure of the network (Simmel 1950) with the tool of the concentric circles, to tip and tail the rich content of the interview. While the visualization of the egonet produced with Netdraw was used as the initial input for the in-depth interview, the target of concentric circles was provided at the end of the interview as a final way to reflect upon the friendship ties previously discussed. Here interviewees balanced out the various nuances of each relationship and consequently placed friends in the circles they considered appropriate, taking also in account other relevant relationships they may have with family, colleagues and other friends. This type of methodological combination has been previously successfully used in various studies on social support: Lubbers et al., (2007) and Dominguez and Maya-Jariego (2008), for example, use egonet visualizations as input for interviews with Latino migrants in Spain and Boston, to discuss respectively the mechanisms of ethnic self-identification and the reciprocal influence between personal networks and the process of acculturation.

\section{Advantages of mixed methods in data collections}

The advantages of using the egonet visualization as a prompt for the collection of qualitative data have been already discussed in the literature, where it's been noticed that visualizations facilitate the mnemonic exercise of remembering alters and the contexts in which relationships are embedded (Hogan et al., 2007); they help to correct errors in the coding of name generators and interpreters (Cheong et al., 2013; Molina et al., 2014); and they provide a new context for the interview, where interviewees are presented with a standardised image of their social world. Such image presents them with new information and insights about themselves, thus shifting their role from being observed to becoming observers (Molina et al., 2014:310). Therefore, visualizations as data collection prompts cannot be considered as neutral instrument for collecting data on pre-existing social networks, but like all the other methodological tools (both qualitative and quantitative) they may exercise an influence on how interviewees perceive and report their social relations (Ryan et al., 2014). respondent to talk about the people named, and to stimulate the discussion about alter-alter ties. In some cases, by looking at the visualization people remembered friends that were not mentioned in the name generator, but sprang to mind when other friends, whom the forgotten ones are related to, were discussed in the interview.

I met Marco because he was a colleague of another guy whom I forgot to mention in the first interview (the name generator). If he knows that I forgot to include him he'd kill me! So please add him to the network, he knows everyone else. Maurizio MD35[2] (male, 35 years old, secondary school, lives alone) 
When presented with the visualization of their egonet, people shifted to the role of observers, as noticed by Molina and colleagues (2014). Interestingly, some people were aware and reasoned in terms of network, grouping friends together and defining the criteria that differentiate the groups. Others tended to talk about one friend per time, and then moved on to a dyadic level, discussing alter's relationships with other friends. The various ways in which people tackled the description of networks could have not been observed with a simple name generator, where interviewees are guided in the process of naming people and indicating alter-alter ties by the standardised format of the questionnaire. While in the traditional name generator each dyad is presented subsequently to the interviewee, the visualizations of the egonet and the following in-depth interviews allow people to discuss dyads and groups in their preferred order of relevance and in different ways: the narratives thus allow distinguishing between dyads and subgroups according to the different ways in which these structural elements are described.

3.10 Vittoria (female, 30 years old, degree, lives alone), for example, has a network composed of a core of intimate friends, and other people scattered around the core, some of which are even called with collective names according to the person who introduced them to her (Fig. 1). Thus there are Simo's friends and Davide's friends. Some other collective nodes are defined by the place where she met them or the activities they share, like the radio she works for, the dance course she attends, people she met when she lived in France, and a group of graffiti writers.

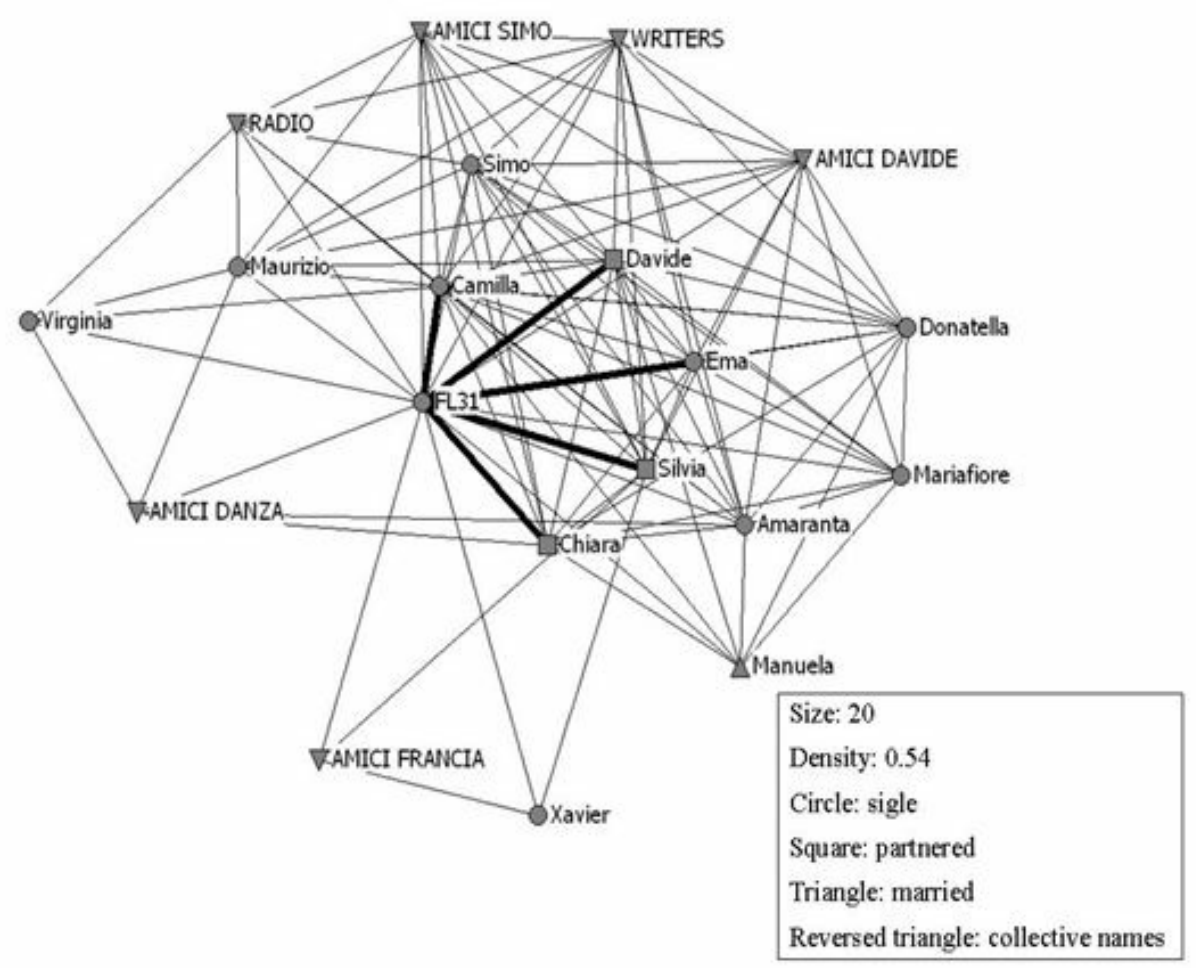

Figure 1. Vittoria's network

\begin{abstract}
This picture is amazing, because (the reality) is exactly like this. There are the intimate friends, the ones who know me better (thicker ties in the network); and then there are the wider circles of friends, people whom I like to go out for a drink, to go to the cinema, to a festival or a gig, but whom I don't see very often for several reasons. Mainly because I don't have enough time, I already have all these friends and others I would like to know better, so I tend to organise events in which I invite them all. Like Davide's friends, I should put them together in a single node, as when I organise a party they always come together. Vittoria FL30
\end{abstract}

3.11 This tendency of clustering together people who are associated in the same group or category was also noticed in the study by Ryan and colleagues (2014), and was interpreted as a strategy adopted by the interviewees to reduce the burden of having to name too many people.

3.12 In the case of Maria (female, 28 years, secondary school, lives with parents) the structure that came out of the name generator indicated a highly cohesive group of friends shaped as a clique, where it is impossible to distinguish between various dyads (Fig. 2). However, during the interview she started talking about each of them separately. While the network structure and visualization do not offer any distinction between cores and peripheries, or components, the narratives suggest a hierarchical ordering of these dyads: the people she felt closer to are discussed earlier in the interview and placed in the inner lines of the target of concentric circles (Fig. 3), while toward the end she discussed people she does not even have a personal relationship with, but who are included as being part of the cohesive structure. She describes one of them, Alessandro, who is placed in the furthest circle of the target, with these words: 

always there, but I don't interact with them; not because I don't get along with them, but just because I have no interest in knowing them better. I don't know why, but there are people I do consider friends, even if I am not interested in knowing what they do with their life. Maria FD28

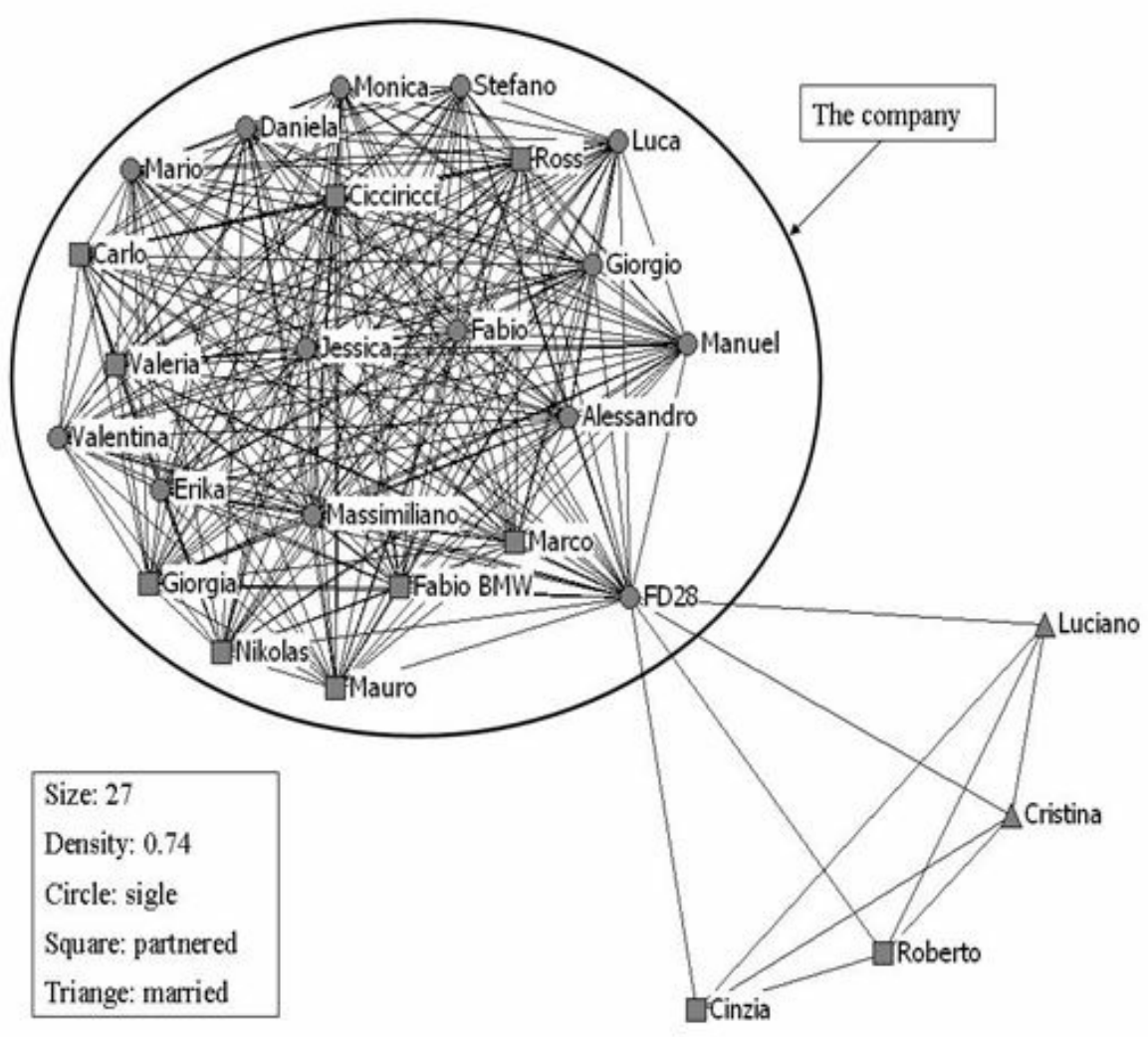

Figure 2. Maria's network 


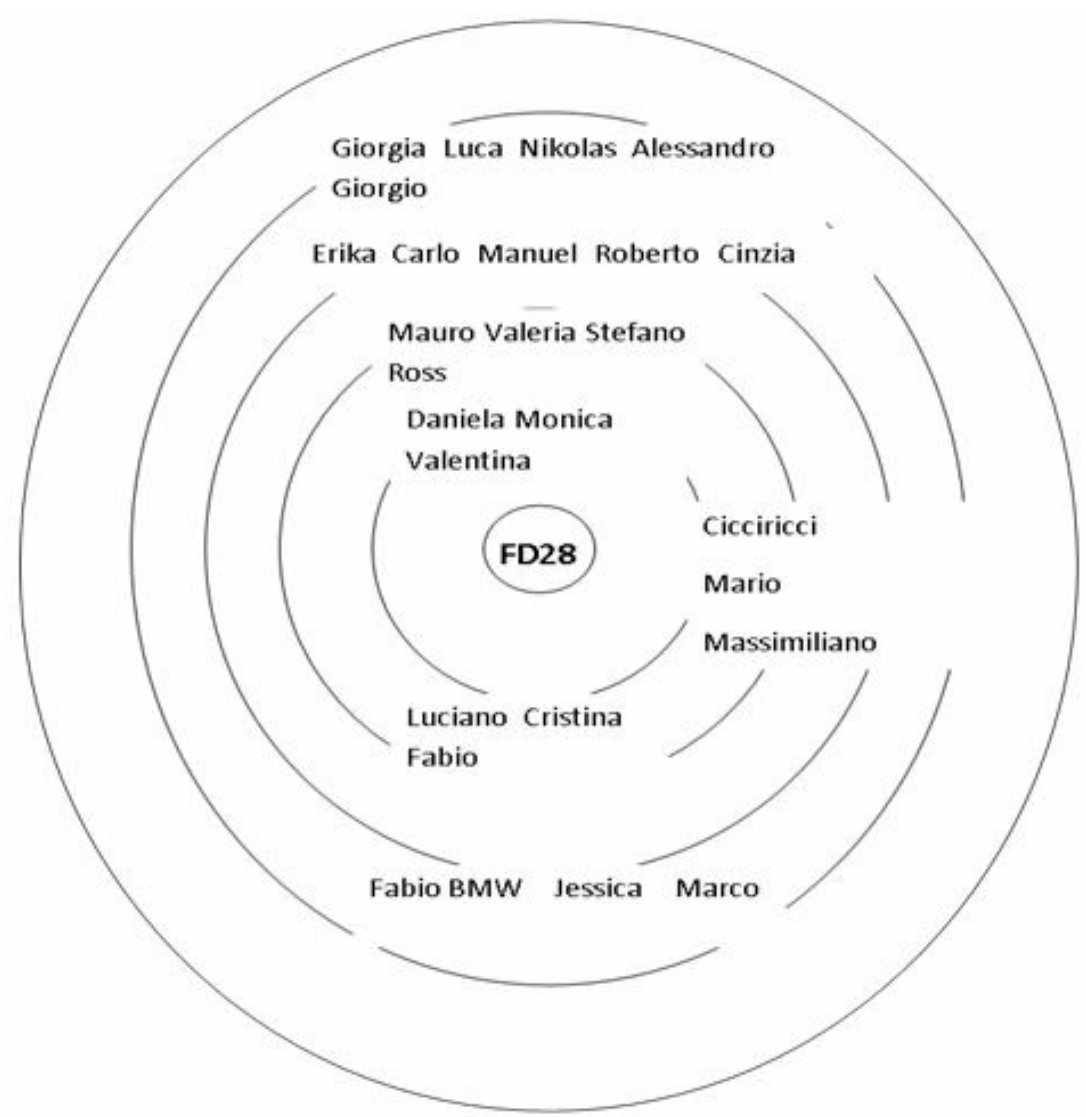

Figure 3. Maria's target of concentric circles

3.13 The ordering and grouping of friends that emerge from the in-depth interview is very often reflected by the positions in which these friends are located in the concentric circles, like in the case of Maria. People whose relationship with is discussed earlier in the interview, and whose narratives occupy more space, are normally located in the circles closer to ego, but there are some exceptions. For example Antonia (female, 30 years old, compulsory studies, lives with parents) firstly and extensively discussed her relationship with Samanta, who used to be Antonia's best friend before they fell out. Despite the fact that the two girls don't see each other anymore, Samanta still occupies a very large portion of the interview, and she is still described as the closest friend Antonia has ever had. However, because she is not a current friend she was not named in the name generator and therefore is not part of the network. She is still located in the concentric circles, although in the furthest circle from ego (Fig. 4). In this example thus, the name generator does not elicit Samanta's name, and her appearance in the furthest position in concentric circles may suggest that she is a distant friend or an acquaintance, but the interview reveals the intensity of the relationship and the centrality of a friend the interviewee lost in the past. 


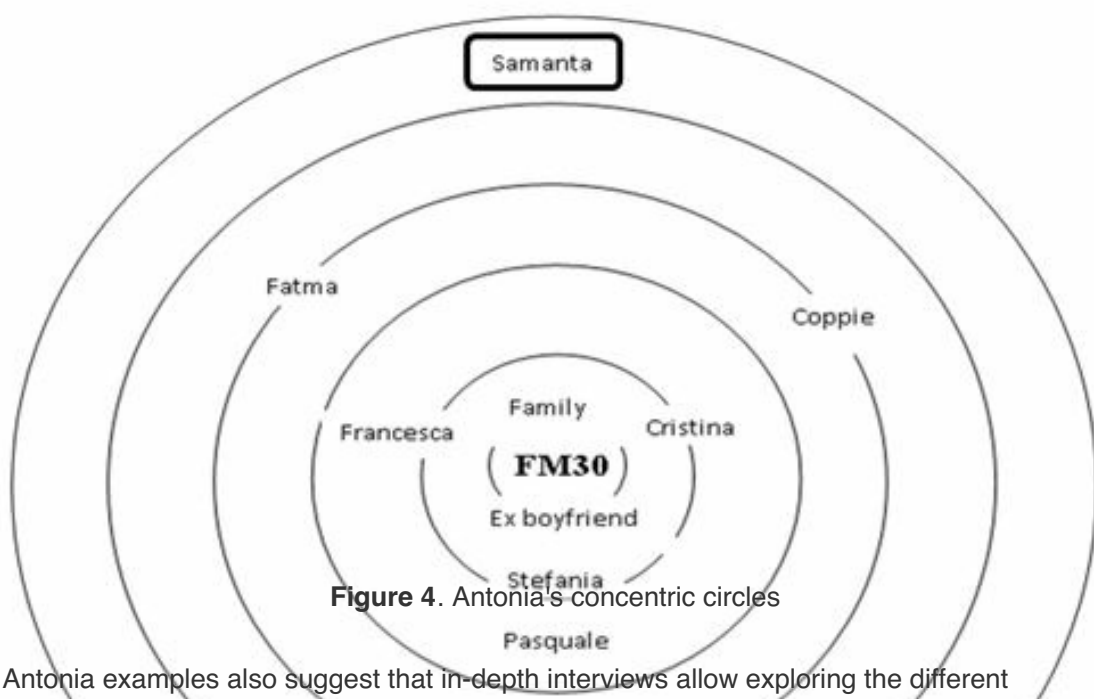

3.14 Maria and Antonia examples also suggest that in-depth interviews allow exploring the different
definitions of friehdship that people adopted when naming their friends, how these definitions impact on the subjective construction of network structures, and how they are reflected in the various forms of visualization. Some respondents named only very few close friends, while others extended the network to a wider range of people they normally interact with, using a more articulated and differentiated definition of friendship (friends they discuss important matters with, friends they share social activities with, friends of friends who they often see, and the like). Some people like Maria and-Antonia reported on relationships with people who are not friends strictly speaking, but are included because they are embedded in highly cohesive friendship networks, or were important in the past. Others named certain friends in the network, and more distant friends in the interview, specifying the criteria of inclusion. For example, Leopoldo's network (male, 31 years old, degree, lives in a shared flat) is composed mainly by a group of friends he has met over 10 years before through basketball (Fig. 5). He recognises them as the core of his friendship circles, who have introduced, over the years, other people in the network, and who also link to other circles of acquaintances.

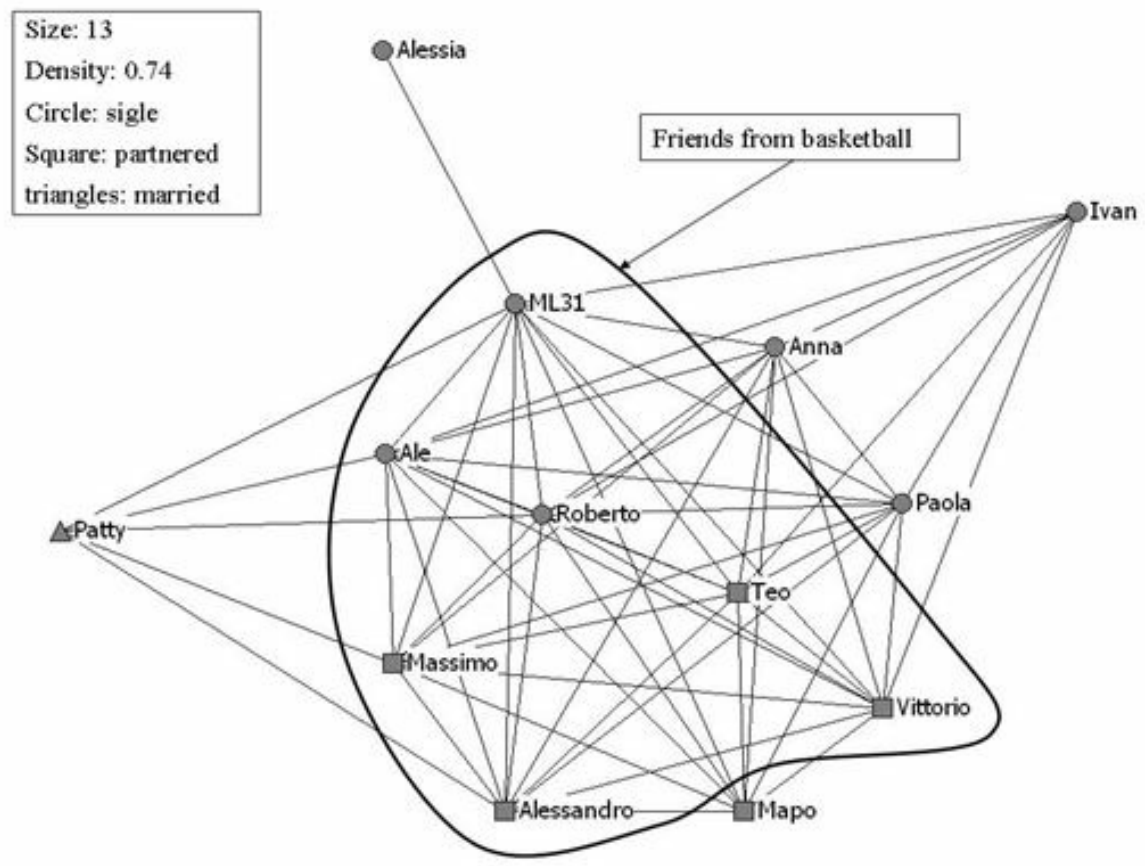


Figure 5. Leopoldo's network

There are the friends I met through basketball, who are the ones I see more often: Massimo, Alessandro, Roberto, Ale, Vitto, Teo. I have known them for a long time, and they became my reference friends, the ones I spend time with. Then there are other people in this network who came into the group through someone of the ones I have already mentioned, or Ivan and Alessia who were introduced by me. I know Ale's friends very well, for example, as we have done many things together, like going on holiday; some of Roberto's friends are in this network and they go out with us. Leopoldo ML31

3.15 While the network structure shows only the core group of friends, whom Leopoldo refers to as 'us', plus some added people (mostly ego's ex-girlfriends), the wider circles of friends of friends are mentioned in the interview but not named in the network. Here the included friends are defined in terms of the length of the relationships (they have known each other for a long time), and the companionship (they spend a lot of time together). Core friends (all male) are collectively grouped as 'us' and distinguished from females (added individually through ego's personal relationships with them) and from the friends of friends, who still hang around with the group quite frequently, but not enough to be part of 'us', and therefore only appear in the in-depth interview and in the subsequent target

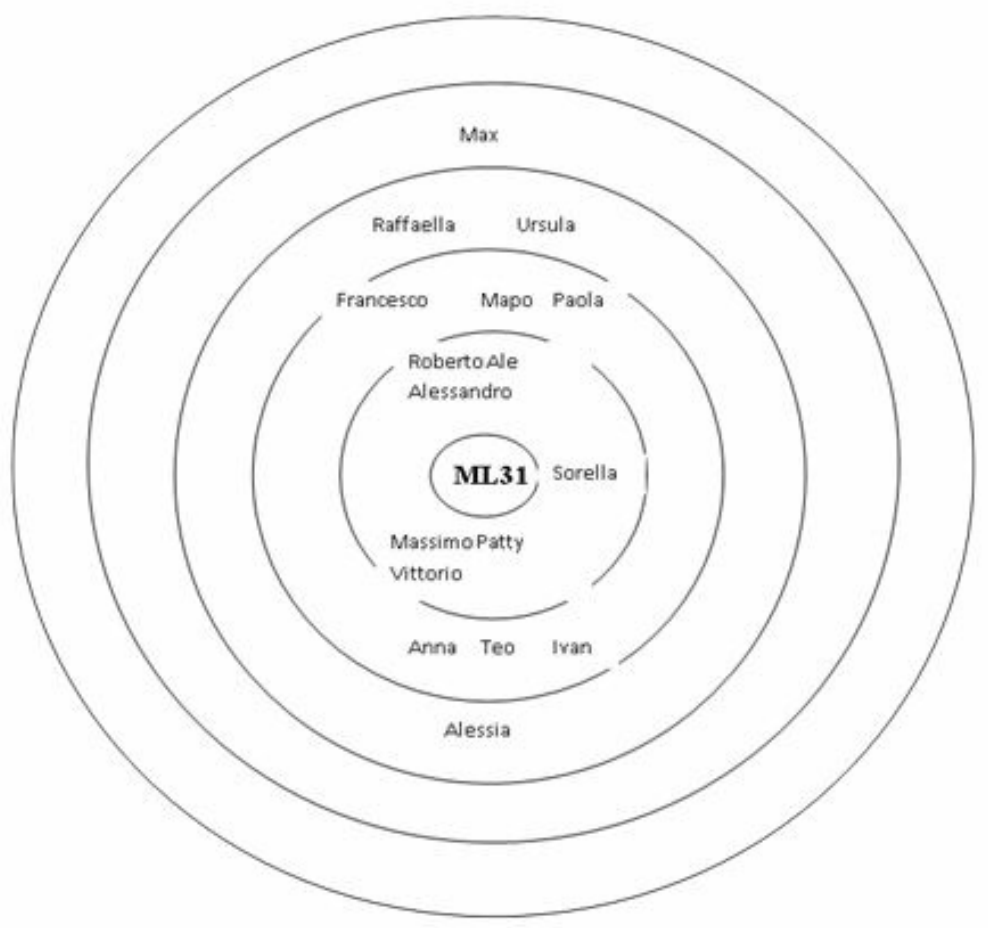

Figure 6. Leopoldo's concentric circles

3.16 Providing the target of concentric circles as a final visual tool in which interviewees could place their friends gave them the advantage of placing these ties in perspective, by weighting them against each other (and therefore placing friends in closer or more distant circles), but also against any other type of important 
relationship. Thus, for example, when family ties were included in this final tool, they were always placed closer to ego than friends. In other occasions, like in the case of Leopoldo, the target gave him the opportunity to place friends who were not important enough to be named in the first visualization, but were subsequently discussed in the interview. Finally, for some people like Antonia the target offered the opportunity to include a former friend who was important in the past and still occupies the furthest circle.

\section{Data analysis}

4.1 Data analysis is conducted by mixing the information gained from name generator and interpreters with qualitative accounts. Alters attributes are used to specify the composition of networks: homophily is calculated for each attribute elicited with name interpreters, producing a detailed description of each structure, and a general overview of the types of friends named. For example, in line with previous research respondents with higher educational background tend to have larger networks (Allan 1979), and they name fewer or no friends who left school after compulsory studies compared to people with lower educational background (Table 1).

Table 1. Total number of named friends by educational background

\begin{tabular}{|l|l|l|l|l|}
\hline Educational background of the interviewee & \multicolumn{4}{|l|}{ Educational background of named friends } \\
\hline & Compulsory school & Secondary school & University Degree & Total \\
\hline Compulsory school (7 cases) & 16 & 27 & 9 & 52 \\
\hline Secondary school (8 cases) & 9 & 72 & 23 & 104 \\
\hline Degree (8 cases) & 0 & 15 & 65 & 80 \\
\hline
\end{tabular}

Along with the classic analysis that can be done on data collected via name interpreters, information from interviews can also be converted in numbers. For example, the context where respondents firstly met their friends are coded in a numerical way (Table 2) and analysed according to gender and educational background. Males tend to meet their friends at school and in the neighbourhood more often than females, who prefer establishing relationships during holidays or through other friends (Table 3).

Table 2. Examples of numerical coding of contexts of meeting

\begin{tabular}{|l|l|l|l|l|l|l|l|l|}
\hline & IC & CO & VI & PA & SC & VZ & AA & RA \\
\hline $\begin{array}{l}\text { "Neri is someone I met at work as he used to be my colleague" Daniele MD34 } \\
\text { "I met Marialuisa ten years ago in the bank where I work. She taught me the } \\
\text { job and passed me information. Then we started to see each other in our free } \\
\text { time, as we share the interest in salsa dance" Monica FL34 }\end{array}$ & & & & & & & \\
$\ldots$ & & & & & & \\
\hline "We met at school, as we were all in the hockey team" Tiziano MD29 & & & & & & & & \\
"I met Giulia at school, and later Silvia through Giulia" Silvia FD35 & & & & & & & & \\
...
\end{tabular}

Labels: $\mathrm{IC}=$ Common interest; $\mathrm{CO}=$ Co-worker; $\mathrm{VI}=$ Neighbour; $\mathrm{PA}=$ Relative; $\mathrm{SC}=$ School; $\mathrm{VZ}=\mathrm{Holiday} ; \mathrm{AA}=$ friends of friends; RA = romantic relationship.

Table 3. Contexts of meeting friends by interviewees' gender and educational background

\begin{tabular}{|c|c|c|c|c|c|c|c|c|c|c|}
\hline & & IC & $\mathrm{CO}$ & VI & PA & $\mathrm{SC}$ & $\mathrm{VZ}$ & $\mathrm{AA}$ & $\mathrm{RA}$ & Tot $^{3}$ \\
\hline Male (12 cases) & $\begin{array}{l}\% \\
\text { (Abs. Val.) }\end{array}$ & $\begin{array}{l}15 \% \\
(20)\end{array}$ & $\begin{array}{l}9 \% \\
(12)\end{array}$ & $\begin{array}{l}14 \% \\
(18)\end{array}$ & $\begin{array}{l}\% \\
(1) \\
\end{array}$ & $\begin{array}{l}25 \% \\
(33)\end{array}$ & $\begin{array}{l}11 \% \\
(15)\end{array}$ & $\begin{array}{l}20 \% \\
(27)\end{array}$ & $\begin{array}{l}5 \% \\
(7)\end{array}$ & $\begin{array}{l}100 \% \\
(133)\end{array}$ \\
\hline Female (11 cases) & $\begin{array}{l}\% \\
\text { (Abs. Val.) }\end{array}$ & $\begin{array}{l}17 \% \\
(23) \\
\end{array}$ & $\begin{array}{l}10 \% \\
(14) \\
\end{array}$ & $\begin{array}{l}6 \% \\
(8) \\
\end{array}$ & $\begin{array}{l}2 \% \\
(3)\end{array}$ & $\begin{array}{l}22 \% \\
(29) \\
\end{array}$ & $\begin{array}{l}13 \% \\
(18) \\
\end{array}$ & $\begin{array}{l}25 \% \\
(33) \\
\end{array}$ & $\begin{array}{l}4 \% \\
(6) \\
\end{array}$ & $\begin{array}{l}100 \% \\
(134) \\
\end{array}$ \\
\hline Compulsory school (7 cases) & $\begin{array}{l}\% \\
\text { (Abs. Val.) }\end{array}$ & $\begin{array}{l}21 \% \\
(13)\end{array}$ & $\begin{array}{l}13 \% \\
(8)\end{array}$ & $\begin{array}{l}28 \% \\
(17)\end{array}$ & $\begin{array}{l}2 \% \\
(1)\end{array}$ & $\begin{array}{l}10 \% \\
(6)\end{array}$ & $\begin{array}{l}7 \% \\
(4)\end{array}$ & $\begin{array}{l}16 \% \\
(10)\end{array}$ & $\begin{array}{l}3 \% \\
(2)\end{array}$ & \begin{tabular}{|l}
$100 \%$ \\
$(61)$
\end{tabular} \\
\hline Secondary school ( 8 cases) & $\begin{array}{l}\% \\
\text { (Abs. Val.) }\end{array}$ & $\begin{array}{l}12 \% \\
(15)\end{array}$ & $\begin{array}{l}12 \% \\
(15)\end{array}$ & $\begin{array}{l}7 \% \\
(8)\end{array}$ & $\begin{array}{l}2 \% \\
(2)\end{array}$ & $\begin{array}{l}13 \% \\
(16)\end{array}$ & $\begin{array}{l}14 \% \\
(17)\end{array}$ & $\begin{array}{l}35 \% \\
(42)\end{array}$ & $\begin{array}{l}5 \% \\
(6)\end{array}$ & $\begin{array}{l}100 \% \\
(121)\end{array}$ \\
\hline Degree ( 8 cases) & $\begin{array}{l}\% \\
\text { (Abs. Val.) }\end{array}$ & $\begin{array}{l}18 \% \\
(15)\end{array}$ & $\begin{array}{l}4 \% \\
(3)\end{array}$ & $\begin{array}{l}1 \% \\
(1)\end{array}$ & $\begin{array}{l}1 \% \\
(1)\end{array}$ & $\begin{array}{l}47 \% \\
(40)\end{array}$ & $\begin{array}{l}14 \% \\
(12)\end{array}$ & $\begin{array}{l}9 \% \\
(8)\end{array}$ & $\begin{array}{l}6 \% \\
(5)\end{array}$ & $\begin{array}{l}100 \% \\
(85)\end{array}$ \\
\hline
\end{tabular}

Labels: $\mathrm{IC}=$ Common interest; $\mathrm{CO}=$ Co-worker; $\mathrm{VI}=$ Neighbour; $\mathrm{PA}=$ Relative; $\mathrm{SC}=$ School; $\mathrm{VZ}=\mathrm{Holiday} ; \mathrm{AA}=$ friends of friends; $\mathrm{RA}=$ romantic relationship. 
Granovetter's claim (1973) that weak ties, rather than strong ones, are better suited to circulate information. $2 \%$ (5) provide at least three type of support, variously combined; $20 \%$ (47) provide two type of support; $61 \%$ (145) specialise in only one type of support; and $15 \%(36)$ do not offer any kind of support, like Maria's friends with whom she does not have any personal relationship.

Within the egonets, support is spread differently for different people. Simone (male, 28 years old, degree, lives with parents), for example, divides his network in three different groups, specialised in the kind of support they provide, and the division is reflected in the network visualization (Fig. 7).

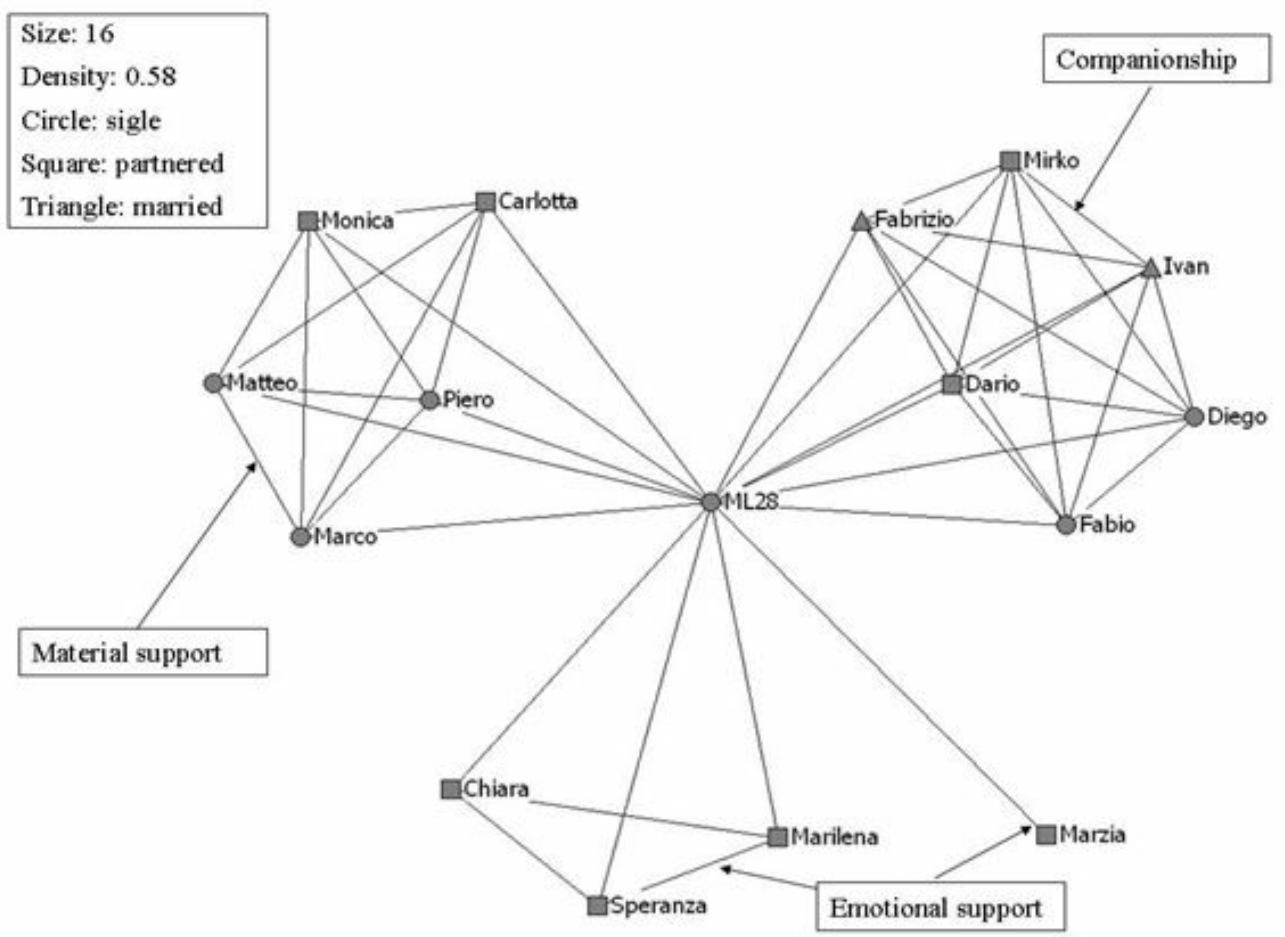

Figure 7. Simone's network

\begin{abstract}
The group on the right is composed by male friends, who only provide companionship as they share activities, go out for drinks, and go on holidays. The group on the left instead is composed by university friends, with whom Simone meets up for preparing exams, sharing lectures' notes, exchanging course books, and the like. The group at the bottom is formed by female friends, and they are the people Simone talks to when he has an intimate problem, as he does not feel comfortable in sharing emotional issues with his male friends.
\end{abstract}

The literature on social support offers useful ways to categorize and interpret personal networks' typologies. As in my case, typologies are usually constructed by combining structural and compositional features of the networks. In Bastani's study of personal networks in Iran (2007), the author finds that middle-class networks in Tehran are similar to western networks in their size, but they differ in structure and composition, presenting densely-knit networks with predominance of kin. A similar study in Germany (Hennig 2007) finds heterogeneous networks of kin, neighbours, friends, and acquaintances, with several degrees of density and with each type of relationship providing different kinds of support. Bernardi et al. $(2007 ; 2014)$ identify three typologies of networks, characterised by various degrees of density and heterogeneity, which exercise different type of influence on couple's fertility decisions and behaviours. Lubbers et al. (2007) identify five typologies based on density, frequency of contact and composition, and measure their effects on ethnic self-identification of migrants in Spain.

Following these examples, for each egonet I calculated size, density and number of components (Tab. 4). These descriptive structural characteristics, combined with qualitative accounts, were used to identify four network typologies: the small clique, and its variation of the star; the company, and its variation of the fragmented group; the core-periphery; and the contextualised components, where subgroups can be defined according to 
various criteria. These are not rigid taxonomies in the sense that a network may straddle two categories or may have evolved from one to another; they are not even exhaustive, as within a larger sample of egonets other types may emerge. For an extended discussion of the friendship typologies see Bellotti (2015).

Table 4. Type of structure, size, density and number of components of egonets.

\begin{tabular}{|l|l|l|l|l|l|}
\hline Name & Code & Type of structure & Size & Density & N. components \\
\hline Marisa & FM31 & Company & 10 & 1 & 1 \\
\hline Leonardo & ML27 & Company & 7 & 1 & 1 \\
\hline Jolanda & FM28 & Company & 6 & 0.86 & 1 \\
\hline Caterina & FD33 & Company & 11 & 0.85 & 1 \\
\hline Leopoldo & ML31 & Company & 12 & 0.78 & 1 \\
\hline Giovanna & FL26 & Company & 20 & 0.75 & 1 \\
\hline Micol & FD28 & Company & 26 & 0.71 & 3 \\
\hline Sebastiano & MM28 & Company & 11 & 0.69 & 1 \\
\hline Daniele & MD34 & Company & 17 & 0.66 & 3 \\
\hline Maurizio & MD35 & Company & 13 & 0.65 & 2 \\
\hline Melissa & FD27 & Contextual components & 6 & 0.66 & 1 \\
\hline Michele & MM34 & Contextual components & 6 & 0.6 & 1 \\
\hline Battista & MD28 & Contextual components & 14 & 0.56 & 1 \\
\hline Simone & ML28 & Contextual components & 15 & 0.26 & 4 \\
\hline Veronica & FL28 & Contextual components & 6 & 0.26 & 3 \\
\hline Vanessa & FL30 & Core-periphery & 19 & 0.49 & 1 \\
\hline Silvia & FD35 & Core-periphery & 15 & 0.33 & 1 \\
\hline Giacomo & MM27 & Fragmented group & 11 & 1 & 1 \\
\hline Alberto & MM32 & Fragmented group & 5 & 1 & 1 \\
\hline Antonia & FM30 & Small clique & 3 & 1 & 1 \\
\hline Tiziano & MD29 & Small clique & 3 & 1 & 1 \\
\hline Marco & ML35 & Small clique & 3 & 1 & 1 \\
\hline Monica & FL34 & Star & 3 & 0 & 3 \\
\hline & & & & \\
\hline
\end{tabular}
and only one component, which represents the group of girls she goes out with. Within these, she differentiates the relationships in terms of closure and intimacy, and the differentiation is reflected in the target of concentric circles (Fig. 8). For example, she does not get along very well with Laura and Cinzia, but they are still named in the egonet because they belong to the clique of the company, which makes relations sticky and hard to break (Krackhardt 1998). Giacomo (MM27, 27 years old, compulsory studies, lives with family) described a network of similar size, density and number of components, but the structure is categorised differently. It is not a company insomuch as it does not include long-term friends who met in childhood or adolescence and have developed a collective sense of belonging and a shared identity over time. It is more like a fragmented group which lacks this specific collective identity, being simply a group of people who tend to frequently interact for common activities or through ego's mediation. 


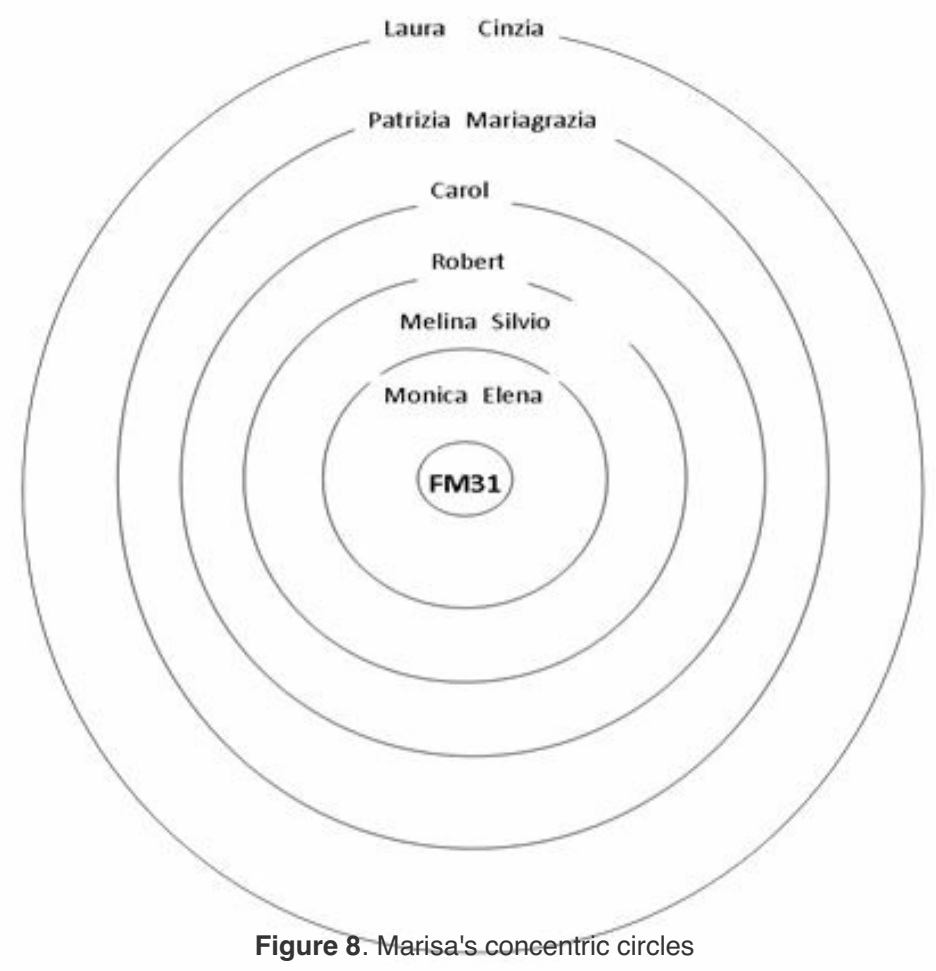

Interestingly, despite the differences in the shapes and meanings of these structures, the concentric circles do not present any significance variance across the interviewees in the way in which they are constructed. Regardless of the typology of the egonet, all the interviewees place their friends in the concentric circles depending on how close they are perceived to be. The differences that a structure like the company has compared to the one of fragmented groups or the one of core-periphery are not reflected in the disposition of people in the concentric circles. While the target visually represents the closure and intimacy of friendship ties ranked against each other, the egonet visualization reveals the organization of relations in groups and cliques.

\section{Advantages of mixed methods in data analysis}

4.9 The name generator and the name interpreters provide measures for the type of social capital that friendship can supply, and the way in which it is embedded in relationships. Formal network analysis allows the researcher to gain an 'outsider' view of the meso level of friendship, where social capital is not accounted only for dyads, but it is distributed across the network. Therefore it is possible to observe if there is any structural specialization in the kind of support provided (like in the previous case of Simone's network), or if the network as a whole fails in providing some kind of needed support (like in the cases of Marco and Antonia presented below). While the shape of the network highlights some important features of this distribution, qualitative accounts are useful to refine the understanding of the composition of social capital, where similar structures can be used for different types of support. Interviewees also provide an insight on the subjective perception of these forms of support, which might disclose satisfaction or bafflement about the quality of friendship.

4.10 For example, the network of Marco (male, 35 years old, degree, lives with parents) and the one of Antonia (discussed before) look exactly the same (Table 4), as they both consist in two small cliques of only three friends. However they are very different in terms of the kind of support provided, as Marco only gain companionship from his friends, and do not like to share intimate issues with them, while Antonia only have intimate friends who lack in providing companionship. In the case of Marco, the support specialization is actively sought in the network, as he does not allow any of his friends to intrude in his intimate life, and conversely he also tends to select friends who do not often ask him for emotional support. The narratives he uses to describe his relationships do not denote any indication of a feeling of lack of support. Conversely, Antonia's narrative shows the frustration for the lack of companionship, as while she can always go around to her friends for a chat she doesn't have anyone to share her interests with.

\footnotetext{
'Interviewer: what do the people you named give to you? Marco: We spend time together... well don't let me reduce it like that, it seems very superficial. But at the very core, I believe everyone intends friendship in his own personal way. With Stefano, for example, there isn't a friendship in the sense of talking about things, as we both are not very talkative. There is reciprocal respect, and there is the tacit agreement of not talking about private matters'. Marco ML35

'I had to calm down: sometimes I used to get up in the morning and wanted to do so many things, then I called them and none of them wanted to do anything. So what was I supposed to do, going out on my own? I used to get incredibly angry, do you know how many times we argued about it? But they are who they are, they don't like to go out, and we rarely go clubbing' Antonia FM30
} 
colleagues, an ex-boyfriend and an ex-friend (Samanta, discussed above). This may indicate Antonia's desire to enlarge the network of friends to gain the companionship she is missing.

\section{Data interpretation}

5.1 As we have seen, personal networks are classified according to their structural properties: size, density, number of clusters, subgroups. A more comprehensive discussion of the various typologies is presented elsewhere (Bellotti 2008; 2015). The combination of the visualization and structural analysis of network shapes with the thematic analysis of qualitative accounts helps with the interpretation of these possible typologies of friendship networks. Overall, mixing the methods has proven to be extremely useful in understanding the peculiarities of these structures, and in suggesting some interesting roles of friendship for single youth.

For example, the status of being single was not a topic that was planned to be explicitly explored during interviews. While people were selected by asking them if they were currently involved in any romantic relationship, the whole data collection process concentrated on friendship. The theme of singleness was left to be accounted at the interviewee's discretion, to see if the role of friends in substituting family ties or partners (which has been noticed in previous researches, see for example Spencer and Pahl 2006; Roseneil and Budgeon 2004; Weeks et al. 2001; Weston 1998) would naturally emerge during the narrative accounts. Most of the people did indeed end up talking about romantic relationships, previous partners, and future expectations.

The combination of network typologies, individual attributes, and the emerging topic of singleness in qualitative accounts is useful to explore some interesting tendencies. People living on their own with a typology of friendship that I called company (like in the case of Maurizio), or a core-periphery structure (like in the case of Vittoria), explicitly describe their friends using family terms, while people still living with their parents, regardless of the network structure, do not use the same metaphor. In other cases, people who identify a special, 'best' friend within the larger circle of friends compare him or her to a partner, discussing the limits and advantages of emotionally investing in such a close, non-romantic relationship. Accordingly, these people rarely add family relationships in the concentric circles at the end of the interview. This does not mean they do not give importance to family ties, but may suggest that friendship has a different and equally important status in their life.

Therefore, the analysis of the structural characteristics on personal networks combined with the analysis of narratives shed a light on some emergent processes that were not at the core of the data collection: while the analysis simply organise the material collected around the research questions that guide the study, further combinations were useful in interpreting some of the unexpected results, like the repercussions on single life, suggesting interesting elements for further investigations.

The combination of narrative accounts with structural properties is also very useful for detecting mechanisms for longitudinal modifications of networks. The information obtained with name generators, unless collected over time, produce a static and cross-sectional representation of what is going on in the life of respondents: qualitative interviews can offer a valid source of information in detecting dynamics and changes (Uzzi 1997; Bidart and Degenne 2005; Bidart and Lavenu 2005; Hollstein 2011, Bernardi et al. 2014). The structure of the interview protocol, and the natural way of accounting for events in personal life, elicit data on network formations and evolutions, and offers a valuable way of interpreting the structural outcome. Interviews also enlarge the perspective of the network, as in the narratives the interviewees call into play other contexts, events and relationships, like family, partners, changes in life patterns, trips and holidays, arguments and crisis.

The case of Giovanna (female, 26 years old, degree, lives with parents) is useful to show how the mixture of information helps with the interpretation of data. Giovanna's network is mainly composed by long term friends from the Jewish community in Milan (Fig. 9), and is categorised in the typology of the company. All her friends went to the same school since they were kids, and developed a long term, intense and highly dense network. While she appreciates the intensity of this group, and the fact that she is still in contact with all her friends even if some of them now live abroad, the structure of the network has affected her in the past. After finishing secondary school, she spent two years in Israel: the experience had a strong impact on her personality, on her relationships with some friends, and on the overall network. She became a more confident person, but she found that people back home did not adapt to her new identity very well, as they were used to consider her in different terms. On the other hand she strengthened the relationships with friends who went with her in Israel, because she could see them in a different context and she better understood their personalities. Moreover, the new improved self-confidence helped her in making new friends outside the Jewish community, and enlarging her social circle with people from different social and cultural backgrounds. 


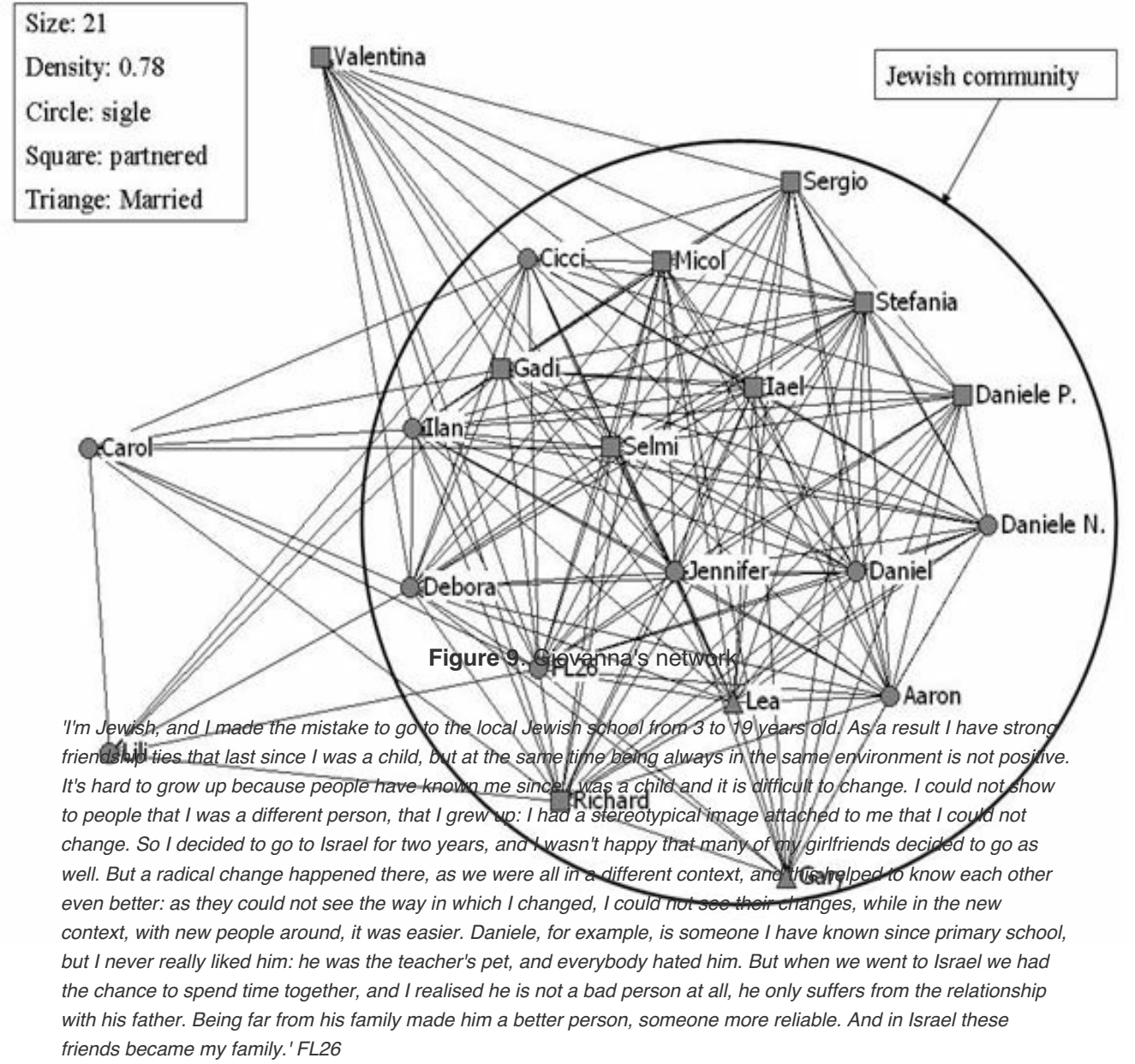

These complementary information help the researcher to understand the social mechanism that shape friendship and to observe the 'shadow network' (Heath et al. 2009), the network of people who are not directly elicited by the name generator, but are subsequently added during the interviews as meaningful actors in explaining specific mechanisms. The target used at the end of the interview collects this complementary information, giving the respondents the chance to place not only friends, but whoever they consider important for their account of friendship.

\section{Advantages of mixed methods in data interpretation}

As we have seen in these previous examples, the combination of qualitative interviews with social network analysis and egonet visualizations proves to be fruitful in the interpretation of data. At the level of analysis this combination mainly consists in recoding qualitative information, in differentiating ties and structures, and in contextualising certain social mechanisms (like in the case of homophily). At the level of data interpretation the advantages are even more consistent, as the mixed method approach can favour the observation of emerging themes that were not explicitly addressed in the data collections. In the case of singleness, the theme only emerged in the accounts of certain interviewees, while others did not mention the topic, although everybody was initially selected on the criteria of not being involved in a romantic relationship. By mixing these narratives with the structural features of friendship networks and with the analysis of their compositions, these variations where interpreted accordingly, and elicit interesting results that opened up further questions.

Also, the narratives helped to illustrate the contextualised nature of these structures: qualitative accounts provide interpretations for the dynamics of networks and for the surrounding people and events that, although not related to friendship strictly speaking, allow a better understanding of some of the mechanisms that guide the formation, evolution and organization of personal networks.

\section{Conclusions}

6.1 Friendship is a complex relationship which provides multidimensional social capital, but it is also an informal type of relationship whose definition emerges and it is negotiated in everyday interactions. Also, like all the other kind of personal relationships, it is dynamic and continuously evolving, going through different phases and facing problems, discussions, changes. But more important, friendship rarely happens in dyads: it normally entails a network of relationships between several kinds of friends, and it is embedded in other relational contexts. 
friendship within these relational contexts, keeping into account the dynamics and multidimensionality of friendship ties. Social network analysis provides formalization and visualization of the shapes of friendship structures offering an 'outsider' point of view, while qualitative accounts investigate the subjective meaning and nuances of friendship ties. In particular, in this paper the advantages in mixing the two methods have been discussed for data collection, data analysis and data interpretation.

For data collection, the combination of the methods allow to understand the various definitions of friendship the interviewees use to include people in their egonets, to distinguish these people from other friends not included in networks but mentioned during the interviews, and to categorise friends according to several kind of attributes. The visualization of the network structure helps the interviewees to identify subgroups and to discuss specific features of friendship ties, to remember people who thy might have forgotten when listing friends, and to organise the narrative of the interview. The target of concentric circles that they fill at the end of the interview helps them to rank their relationships against each other and against further important people.

For data analysis, the combination of the methods allows to explore the distribution of social capital, its composition and the subjective perception that people express about the different kind of resources provided by friends. It also allows to understand the similarities and differences of networks' typologies, and to differentiate structures that look formally identical. Again, the visualizations facilitate the distinction of type of supports and of similar structures.

Finally, for data interpretation, qualitative accounts facilitate the extension of the analysis to emerging themes and to networks' dynamics, and how these features impact personal networks. The visualization of the target alows the interviewees to add people that were not initially listed in the name generator, but emerged as important during the interview.

However, combining social network analysis with qualitative methods does have limits. In the examples described in this paper, an egonet approach was selected: this means that the information were entirely subjective, and do not represent the point of view of other people in the network. We do not know, for example, if friendship is reciprocated, if some dynamics would be accounted differently by the people named in the networks, and if the interviewee is fully aware of the details of alter/alter ties. Therefore, data can only tell the story of ego's view of friendship, which might be different from his/her friends' point of view.

Also, like in most qualitative studies, the selected sample is small and not representative. It is used to explore the topic of friendship, without the demanding of being exhaustive: other people might have different networks' shapes, different definitions of friendship, and different opinions on the topic. Formalising the data collection in a way that is extendible to larger samples implies most of the time abandoning the idea of using qualitative methods, even if qualitative exploratory research like the one presented here can be used to construct more refined standard questionnaires to be used with larger samples, and questionnaires can also include a variety of open questions, to be analysed with qualitative methods and subsequently recoded in numerical form.

Despite the limits, mixing social network analysis with qualitative methods and various forms of visualization is a fruitful area of research, which can take into account at the same time the structural possibilities and constrains embedded in personal networks, and the subjective ways in which people perceive and describe such possibilities and constrains.

\section{Notes}

Although the term 'relational sociology' here refers to a specific sociological stream, all social network analysis takes indeed a relational approach, which is what distinguishes it from variable analysis (Bellotti 2015).

Interviews are coded with a letter indicating gender $(F / M)$, a letter indicating level of education $(M=$ compulsory school/D = secondary school $/ L=$ degree) and a number indicating the age of the interviewee.

The total number of people in this case (267) is not the same of the total number of named people (236). This is due to the fact for some friends the meeting happened in a multiplex context: school friends can also be neighbors, or coworkers might share interests. In these cases relationships are counted for more than one context, for example both in 'school' and 'neighbors'.

\section{References}

AGNEESSENS, F. (2006) Social Capital in Knowledge Intensive Teams: The Importance of Content, Structure and Resources for Performance of Researchers at University. Ghent University: Doctoral Dissertation.

ALLAN, G. (1979) A Sociology of Friendship and Kinship London: George Allen and Unwin. 
BELLOTTI, E. (2015) Qualitative networks. Mixed methods in sociological analysis London, Routledge.

BELLOTTI, E. (2008) What are friends for? Elective communities of single people.Social Networks, 30, 4, p. 318329. [doi:10.1016/j.socnet.2008.07.001]

BASTANI, S. (2007) Family comes first: Men's and women's personal networks in Tehran.Social Networks, 29, 3, p. 357-374. [doi:10.1016/j.socnet.2007.01.004]

BERNARDI, L., Keim, S. \& von der Lippe, H. (2007) Social influences on fertility: a comparative mixed methods study in eastern and western Germany. Journal of Mixed Methods Research, 1, 1, p. 23-47. [doi:10.1177/2345678906292238]

BERNARDI, L., Keim, S. \& Klärner, A. (2014) Social networks, social influence, and fertility in Germany: challenges and benefits of applying a parallel mixed methods design. . In (eds) S. Dominguez \& B. Hollstein, Mixed-Methods Social Network Research. New York: Cambridge University Press. [doi:10.1017/cbo9781139227193.008]

BIDART, C. \& Degenne, A. (2005) Introduction: the dynamics of personal networks.Social Networks, 27, p. 283287. [doi:10.1016/j.socnet.2004.11.006]

BIDART, C. \& Lavenu, D. (2005) Evolution of personal networks and life events.Social Networks, 27, p. 359 ?376. [doi:10.1016/j.socnet.2004.11.003]

BODIN, ? \& Tengö, M. (2012) Disentangling intangible social-ecological systems.Global Environmental Change, 22, 2, p. 430-439. [doi:10.1016/j.gloenvcha.2012.01.005]

BORGATTI, S.P. (2002) NetDraw: Graph visualization software. Harvard, MA: Analytic Technologies.

BRINT, S. (1992) Hidden meanings: cultural content and context in Harrison White's structural sociology. Sociological Theory, 10, p. 194-208. [doi:10.2307/201958]

CHEONG, L., Armour, C. \& Bosnic-Anticevich, S. (2013) Primary health care teams and the patient perspective: a social network analysis. Research in Social and Administrative Pharmacy, 9, p. 741-757 [doi:10.1016/j.sapharm.2012.12.003]

CHIU, L. F. \&West, R.W. (2007) Health Intervention in social context: Understanding social networks and neighbourhood. Social Science and Medicine, 65, p. 1915-1927. [doi:10.1016/j.socscimed.2007.05.035]

COVIELLO, N. (2005) Integrating Qualitative and Quantitative Techniques in Network Analysis. Qualitative Market Research, 8, 1, p. 39-60. [doi:10.1108/13522750510575435]

CRESWELL, J. W., \& Plano Clark, V. L. (2007)Designing and conducting mixed methods research. Thousand Oaks, CA: Sage.

CROSSLEY, N., Bellotti, E., Edwards, G., Koskinen, J., Everett, M. \&Tranmer, M. (2015)Social Network Analysis for ego-nets. Sage: London.

CROSSLEY, N. (2010) The Social World of the Network: Combining Quantitative and Qualitative elements in Social Network Analysis. Sociologica, 1.

CROSSLEY, N. (2011) Toward relational sociology. Routledge: London.

D'ANGELO, A. \& Ryan, L. (2016), Social Network Analysis: a Mixed Methods Approach. In (eds) L. McKie, L. Ryan, An End to the Crisis in Empirical Sociology?London: Routledge.

DOMINGUEZ, S. \& Maya-Jariego, I. (2008) Acculturation of host individuals: immigrants and personal networks. American Journal of Community Psychology, 42, 3-4, p. 298-308. [doi:10.1007/s10464-008-9209-5]

DOMINGUEZ, S. \& Hollstein, B. (eds) (2014)Mixed-Methods Social Network Research. New York: Cambridge University Press. [doi:10.1017/CBO9781139227193]

EDWARDS, G. (2010) Mixed-Method Approaches to Social Network Analysis. Review paper, ESRC National Centre for Research Methods.

EMIRBAYER, M. \& Goodwin, J. (1994) Network Analysis, Culture and the Problem of Agency.American Journal of Sociology, 99, p. 1411-54. [doi:10.1086/230450]

EMIRBAYER, M. (1997) Manifesto for a relational sociology. American Journal of Sociology, 103, p. 281-317. [doi:10.1086/231209]

FISCHER, C.S. (1982) What do we mean by 'friend'? An inductive study.Social Networks, 3, p. 287-306. [doi:10.1016/0378-8733(82)90004-1]

FUHSE, J. \& Mützel, S. (2011) Tackling connections, structure, and meaning in networks: quantitative and qualitative methods in sociological network research. Quality \& Quantity, 45, p. 1067-89.

[doi:10.1007/s11135-011-9492-3] 
GRANOVETTER, M. (1973) The Strength of Weak Ties? American Journal of Sociology, 78, p. 1360-1380. [doi:10.1086/225469]

GUBA, E.G. \& LINCOLN, Y.S. (1994) Competing paradigms in qualitative research. In (eds) N.K. Denzin \& Y.S. Lincoln, Handbook of Qualitative Research. Thousand Oaks, CA: Sage.

HEATH, S., Fuller, A., \& Johnston, B. (2009) Chasing Shadows: Exploring network boundaries in qualitative social network analysis. Special Issue of Qualitative Research, 9, 5, p. 645-661

HENNIG, M. (2007) Re-evaluating the Community Question from a German perspective. Social Networks, 29, 3 , p. 375-390. [doi:10.1016/j.socnet.2007.01.008]

HOGAN, B., Carrasco, J. A \& Wellman, B. (2007) Visualizing personal networks: working with participant-aided sociograms. Field Methods, 19, p. 116-144. [doi:10.1177/1525822X06298589]

HOLLSTEIN, B. (2014) Mixed methods social network research: an introduction. In (eds) S. Dominguez \& B. Hollstein, Mixed-Methods Social Network Research. New York: Cambridge University Press. [doi:10.1017/cbo9781139227193.003]

HOLLSTEIN, B. (2011) Qualitative Approaches. In (eds) J. Scott \& P. J. Carrington,The Sage handbook of Social Network Analysis. London: Sage. [doi:10.4135/9781446294413.n27]

JACK, S. L. (2005) The Role, Use and Activation of Strong and Weak Network Ties: A Qualitative Analysis. Journal of Management Studies. 42, 6. p. 1233-1259. [doi:10.1111/j.1467-6486.2005.00540.x]

KAHN, R. L. \&Antonucci, T. C. (1980) Convoys over the life course: Attachment, roles, and social support. In (eds) P. B. Baltes \& O. Brim, Life-span development and behaviour (Vol. 3). New York: Academic Press.

KIRKE, D. (2010) Comment on Nick Crossley/2. Sociologica, 1.

KNOX, H., Savage, M. \&Harvey, P. (2006) Social networks and the study of relations: networks as method, metaphor and form. Economy and Society, 35, 1, p. 113-140. [doi:10.1080/03085140500465899]

KRACKHARDT, D. (1998) Simmelian tie: super strong and sticky. In (eds) R. Kramer \& M. NealePower and Influence in Organizations. Thousand Oaks: CA: Sage.

LAZEGA, E., Jourda, M. T., Mounier, L. \&Stofer, R. (2008) Catching up with big fish in the big pond: Multi-level network analysis through linked design. Social Networks, 30, p. 157-76.

[doi:10.1016/j.socnet.2008.02.001]

LUBBERS, M., Molina, J. L. \& McCarty, C. (2007) Personal networks and ethnic identifications: the case of migrants in Spain. International Sociology, 22, 6, p. 720-740. [doi:10.1177/0268580907082255]

LUBBERS, M., Molina, J. L., Lerner, J., Brandes, U., Avila, J. \& McCarty, C. (2010) Longitudinal Analysis of personal networks. The case of Argentinean Migrants in Spain. Social Networks, 32, 1, p. 91-104. [doi:10.1016/j.socnet.2009.05.001]

MARSDEN, P. (2003) Interviewer Effects in Measuring Network Size Using a Single Name Generator.Social Networks, 2, 5, p. 1-16. [doi:10.1016/S0378-8733(02)00009-6]

MARTINEZ, A., Dimitriadis, Y., Rubia, B., Gomez, E. \& de la Fuente, P. (2003) Combining qualitative evaluation and social network analysis for the study of classroom social interactions. Computers and Education, 41, p. 353-368. [doi:10.1016/j.compedu.2003.06.001]

MCCARTY, C. (2010) Comment on Nick Crossley/3.Sociologica, 1.

MISCHE, A. \& White, H (1998) Between Conversation and Situation: Public Switching Dynamics Across Network-Domains. Social Research, 65, p. 295-324.

MISCHE, A. (2003) Cross-Talk in Movements. In (eds) M. Diani \&D. McAdam,Social Movements and Networks. Oxford: Oxford University Press.

MISCHE, A. (2011) Relational Sociology, Culture, and Agency. In (eds)J. Scott \& P. Carrington,The Sage Handbook of Social Network Analysis. London: Sage Publications. [doi:10.4135/9781446294413.n7]

MITCHELL, J.C. (ed.) (1969) Social Networks in Urban Situations. Manchester: Manchester University Press.

MOLINA, J. L., Maya-Jariego, I. \& McCarty, C. (2014) Giving Meaning to Social Networks: Methodology for Conducting and Analyzing Interviews based on Personal Network Visualizations. In (eds) S. Dominguez \& B. Hollstein, Mixed-Methods Social Network Research. New York: Cambridge University Press. [doi:10.1017/cbo9781139227193.015]

MØNSTED, M. (1995) Processes and Structures of networks: reflections on methodology.Entrepreneurship and Regional Development, 7, p. 193-213. [doi:10.1080/08985629500000013]

RILES, A. (2001) The Network Inside Out. Ann Arbor, MI: University of Michigan Press. 
RORTY, R. (1980) Philosophy and the mirror of nature. Oxford: Blackwell.

ROSENEIL, S. \& Budgeon, S. (2004) Cultures of intimacy and care beyond "the family": personal life and social change in the early 21 st century. Current Sociology, 52, p. 135-59. [doi:10.1177/0011392104041798]

RYAN, L., Mulholland J. \& Agoston A. (2014). Talking ties: Reflecting on network visualisation and qualitative interviewing. Sociological Research Online, 19, 2, 16 http://www.socresonline.org.uk/19/2/16.html 10.5153/sro.3404 [doi:10.5153/sro.3404]

SIMMEL, G. (1950) The Sociology of Georg Simmel, New York: Free Press.

SPENCER, L. \& Pahl, R. (2006) Rethinking Friendship: Hidden Solidarities Today. New Jersey: Princeton University Press.

SPRADLEY, J.P. (1979) The Ethnographic Interview. New York: Holt Rinehart and Winston.

TASHAKKORI, A. \& Creswell, J. W. (2007) Exploring the nature of research questions in mixed methods research. Journal of Mixed Methods Research 1, p. 207-211. [doi:10.1177/1558689807302814]

TASHAKKORI, A. \&Teddlie, C. (1998) Mixed Methodology: combining qualitative and quantitative approaches London: Sage.

TUBARO, P., RYAN, L. \& D'ANGELO, A. (2016) The visual sociogram in qualitative and mixed-methods research. Sociological Research Online. http://www.socresonline.org.uk/21/2/1.html.

UZZI, B. (1997) Social structure and competition in interfirm networks: The paradox of embeddedness. Administrative Science Quarterly, 42, 1, p. 35-67. [doi:10.2307/2393808]

WEBB, B. \& WEBB, S. (1932), Methods of social study. London: Longmans Green.

WEEKS, J., Heaphy, B. \& Donovan, C. (2001) Same Sex Intimacies: families of choice and other life experiments. London: Routledge. [doi:10.4324/9780203167168]

WELLMAN, B. (1979) The community question: the intimate networks of east Yorkers. American Journal of Sociology, 84, 5, p. 1201-1231. [doi:10.1086/226906]

WELLMAN, B. (1990) Different strokes from different folks: community ties and social support.American Journal of Sociology, 96, 3, p. 558-588. [doi:10.1086/229572]

WESTON, K. (1998) Longslowburn: sexuality and social science. New York: Rutledge.

WHITE, H. C. (2008 [1992]) Identity and Control. Princeton, NJ: Princeton University Press.

WHITE, H. C., Boorman S. \& Breiger R. (1976) Social structure from multiple networks: blockmodels of roles and positions. American Journal of Sociology, 81, p. 730-780. [doi:10.1086/226141]

WHYTE, W. F. (1943) Street Corner Society. The social structure of an Italian slum Chicago: University of Chicago Press.

WOO PARK, H. \& Kluver, R. (2009) Trends in online networking among South Korean politicians. A mixedmethod approach. Government Information Quarterly, 26, p. 505-515. 